\title{
Analysis of New Media Marketing Strategy under the Information Age Chang Liu $^{1, a}$ \\ ${ }^{1}$ Beijing Polytechnic College, Beijing, 100000 \\ aemail,
}

Keywords: New Media, Marketing Strategy, Information Age

\begin{abstract}
The emergence of new media, changing the traditional marketing model of a single situation, enriched the form of marketing. Compared with the traditional marketing model, new media marketing is more concerned about the professional level of marketing staff. In addition, the new media marketing to information technology as a technical support, the use of network unbounded communication characteristics, weakened the marketing market segmentation, and promote international cooperation, so that the marketing market into the world. The concept of the world as a big market has also increased the market competition between enterprises, increasing the difficulty of marketing work. This paper will combine the specific definition of new media in the information age and the definition of new media marketing, and explore the strategies and strategies of new media marketing based on the information age.
\end{abstract}

\section{Introduction}

The fastest growing information age is the media, the current media, with a strong interaction, regional, timeliness. Internet users can communicate through information, establish a contact platform, by talking their own interests and so on, all-round participation activities. In the information age media marketing, the user and the media is not the relationship between the employment, the media is only a communication platform, and the media's information content is produced by the user and provided to the media, so that the user is information Of the recipient, the maker and the communicator. Information age media has two characteristics, the user to create media content, the user choose the media communication, that is, the source of information and communication direction are determined by the user's own. And the traditional media to compare the information age of the media has a great advantage, its advantages highlighted in the marketing. Because under the influence of the information age, the number of users is great, and there is no time and space constraint the audience also contains the various levels of society. So, at any time, any place, the media can be flexible and free operation without time, space constraints, such as micro-blogging is a very good media. At the same time, the media information is also varied, not only rich in content spread the form is also a variety of styles. The traditional media needs to be limited by the layout, columns, etc., the information age of the media, you can use the Internet this effective platform to publish a variety of forms, with rich content information. Information media in the information age is extremely fast, its scope of influence is very wide, in many users, the audience under the influence of its power is amazing. Through the emerging media, you can spread the company's products or ideas, has a very good communication.

\section{New Media Features}

1) wide audience range new media has more audiences than traditional media. According to statistics, the number of domestic Internet users has exceeded 600 million people, including mobile phone network and broadband Internet users. 2) across time and space. The emergence of new media breaks the time and space constraints, the audience through mobile devices, anytime, anywhere to browse the relevant information. 3) Strong interaction. New media to make the Internet more interactive, become the traditional way of individual transmission, the audience can choose a certain type of information, and the evaluation of the message to express personal views, but also to achieve communication with other audiences. 4) intuitive and strong. The use of new media 
technology, can achieve the text, pictures, sound and other forms of information to achieve the transmission and exchange, with a strong intuitive. 5) Economy. New media through the Internet for information dissemination, compared with the traditional media, can reduce the human, material and financial resources, with high economy. 6) High efficiency. New media use of computing and network technology, which is extremely rich in the amount of information stored for consumers to carry out targeted search, query, so that the needs of the audience to be highly effective. 7) multimedia display. New media in the form of information dissemination is extremely rich, including images, sound, text and other forms, and can also use a variety of forms to achieve interactive information exchange. 8) technical. The premise of new media marketing is to have a high level of technical support, so in the new media marketing, companies must have high-tech personnel.

\section{The Current Status of New Media Marketing and Development Status}

RSS marketing is mainly based on the common interest of the target group, as its marketing cut entrance, with a strong pertinence, in the news sites, portals, blogs are more common. However, there is no more marketing group is good at using this marketing approach. Thus on the site, through this way the marketing activities carried out, the effect is very obvious. At the same time, but also because of its marketing approach to the use of fewer groups, in a period of time, it is difficult to be universal.

WIKI marketing, mainly through the user's own direct marketing activities, through the WIKI tools will need to promote the product or related services information added, and accompanied by the corresponding pictures, text or links, to achieve the purpose of marketing. For example, Baidu Encyclopedia is one of the tools for WIKI marketing, through Baidu Encyclopedia to add personal or company and product information, they use the form, to achieve interaction with the target group, so as to achieve the purpose of marketing. However, the actual development of the status quo and RSS marketing situation is relatively close to WIKI marketing expertise professionals less, and to ensure that this marketing approach to achieve the desired results, must be skillfully edit key words to ensure that the information issued by the effective Included, and easy to be searched by Internet users.

Blog marketing form more, mainly for the text matching search, hard and so on. Among them, the hard marketing practice is relatively simple, the most common click pay mode, but this model can not effectively meet the growth process of enterprises, the rapid growth of marketing needs. And compared to the two marketing methods, the application of blog marketing is more popular, many people have a certain understanding of this marketing approach. Through the text matching way, lock the target group, and through the common topic of information analysis, to understand the hidden user needs. Therefore, in the form of text matching blog marketing, can more accurately target the consumer groups. However, due to the rapid development of computing network technology, all kinds of new software research and development and promotion, blog users have been replaced by a large number of users, blog marketing heat also will be reduced.

At present, in the new media marketing, micro-blogging marketing the most widely used. Compared to other new media marketing, micro-blogging marketing is to meet the needs of more Internet users. Micro-blogging is a fair individual as the main target, each user can be through the micro-blogging platform, free expression of personal views and views on the community, its mode of operation and published information open and transparent. Enterprises and individuals released by the state, all users can access, and also through the platform to achieve the exchange and interaction between users. Micro-blogging marketing requires less cost, with less manpower and financial investment, and can get excellent marketing results. SMS marketing is mainly through the target group to send marketing SMS form, to achieve the marketing effect. Its marketing operation and e-mail marketing is more similar to the marketing before the need for the user's preferences, consumer demand for detailed data analysis, on this basis, to make targeted planning, it is possible to achieve the desired marketing results. If only blindly large-scale mass marketing SMS, not only marketing effect is not high, but also very likely to trigger the user's disgust. 


\section{New Media Marketing Strategy}

Market division is through the consumer demand, buying habits and other aspects of the survey, according to a certain standard of consumers divided into different consumer groups, so as to define different market categories. New media market is more complex than the traditional market, but also because it is a virtual market, which are more uncertain factors, consumer needs are more variable, so companies want to take new media marketing, the first thing to do is Market division work. How specific the new media marketing market is divided according to the type of product produced by the enterprise, different types of products need to develop different market division standards. At present, the network market model mainly B2B, B2C, C2B, C2C and several other, but specific to a product, in addition to considering the network market model factors, but also consider the product sales target this key factor.

New media marketing target market refers to the enterprise in order to meet the goal of achieving the maximum benefit is expected to set the target marketing object. New media marketing target market choices are generally in accordance with the following procedures: First, enterprises should be based on past sales experience and product type, to determine the main consumer groups; and then through the new media to collect information about product information and consumer information Can bring benefits for the enterprise; Finally, taking into account the various consumer groups and the actual situation of enterprises and other aspects of information to determine the new media marketing target market.

New media marketing market positioning will rationalize the enterprise in the future competition in the industry in an undefeated position. In fact, the new media marketing market positioning is the process of grasping the consumer psychology. If the enterprise can accurately grasp the consumer's consumer psychology, you can accurately predict the sales of the product. Enterprise new media marketing market positioning, including two levels of positioning: one is the initial positioning, this situation is the first time for the use of new media marketing companies, such enterprises do not have the experience of new media marketing, so the enterprise Need to invest a lot of energy to study the consumer psychology and the marketing of competitors; the other is re-positioning, which is for the new media marketing experience of the enterprise. Need to reposition the enterprises to change the needs of consumers and related industries and other aspects of the development trend of a new understanding and understanding to ensure that the new media marketing target market positioning accuracy.

The traditional marketing model is more concerned about the interests of enterprises, while ignoring the interests of consumers, this marketing model is not conducive to the long-term development of enterprises. In the new media era, only to increase the focus on consumer and social interests, it is possible to achieve better development of enterprises. In the pursuit of personalization today, the new media marketing began to focus on customer service business, various forms of customer service continue to emerge, but the basic idea is to emphasize the consumer "one to one" service, so that consumers feel Business in good faith, to win the trust of consumers. Enterprise is currently more commonly used customer service methods are based on network technology, such as 24-hour online customer service, thematic forums, FAQ and so on. In the information age, do a good job of customer service is to strengthen the corporate brand credibility of the key links, not business neglect.

\section{Conclusion}

New media era, the information update speed continues to accelerate, the new media marketing this new marketing model compared with the traditional marketing way to show a strong advantage, and gradually accepted by people. At present, the way the new media marketing is still increasing, the scope of marketing products is also increasing, has become the mainstream of future marketing. Therefore, how to use the advantages of new media to carry out product marketing activities should be at this stage the first thing to consider. 


\section{References}

[1] Wang Kejia. Information age new media marketing strategy [J]. Communication and Copyright, 2013 (03)

[2] Ren Haoran. Innovative practice of enterprise economic management in information age [J]. National Circulation Economy, 2017 (03)

[3] To Yu Yu. On the network information age on the impact of news [J]. Technology Information, $2011(12)$

[4] rain village. We are farewell to the information age [J]. International Journal, 2001 (01)

[5] Zhongxiao Ban. Information Age [J]. Management Science Abstracts, 1998 (11)

[6] Wang Mingli. Information age radio station construction and development prospects [J]. Heilongjiang Science and Technology Information, 2013 (23) 